\title{
Analisis Pengaruh Rasio Keuangan Terhadap Kinerja Bank Umum di Indonesia
}

\author{
(Analysis of Financial Ratio Influenca on the Commercial Bank in Indonesia) \\ Rebecca Stephani, Moh. Adenan ${ }^{1}$, Anifatul Hanim \\ Program Studi Ekonomi Pembangunan Fakultas Ekonomi dan Bisnis, Universitas Jember (UNEJ) \\ Jln. Kalimantan 37, Jember 68121 \\ E-mail: rebeccastephani@yahoo.co.id
}

\begin{abstract}
Abstrak
Bank merupakan industri yang kegiatan utamanya adalah penghimpunan dana dari masyarakat kemudian menyalurkannya dengan tujuan untuk memperoleh pendapatan. Bisnis bank adalah salah satu bentuk usaha yang menjual jasa kepercayaan dari dan untuk masyarakat. Profitabilitas adalah salah satu indikator untuk mengukur kinerja bank yang dalam penelitian ini digunakan Return On Asset (ROA). ROA merupakan alat untuk mengukur kemampuan manajemen bank dalam memperoleh keuntungan dari total asset yang dimiliki. Semakin besar ROA semakin baik tingkat keuntungannya. Tujuan dari penelitian ini adalah untuk membuktikan pengaruh rasio keuangan Biaya Operasional dan Pendapatan Operasional (BOPO), Net Interest Margin (NIM), Non Performing Loan (NPL) dan Loan to Deposit Ratio (LDR) terhadap kinerja bank yang diukur dengan Return On Asset (ROA) serta variabel-variabel manakah yang paling dominan berpengaruh terhadap Return On Asset (ROA). Penelitian ini berfokus pada analisis deskriptif kuantitatif dengan menggunakan metode Ordinary Least Square (OLS). Penelitian menghasilkan secara parsial NPL dan NIM berpengaruh positif dan tidak signifikan terhadap ROA, namun untuk LDR dan BOPO berpegaruh negatif dan signifikan terhadap ROA.
\end{abstract}

Kata Kunci: rasio-rasio keuangan, dan kinerja bank.

\begin{abstract}
Banks is an institution, which has mainly activity is fund deposit from people then credit it for them in generating income. The business is a kind service provider from and into people so it needs public trust. Profitability is one of indicator appropriate to measure the bank performance. Return on Assets (ROA) is measure ability of the bank's management in benefits through total assets owned. The greater the ROA shows the better financial performance due to the greater profit. The purpose of this research is to prove the effect of Operating Expenses and Operating Income Ratio, Net Interest Margin (NIM), Non-Performing Loan (NPL) and Loan to Deposit Ratio (LDR) on bank performance measured by Return On Asset (ROA). The study focused on descriptive quantitative analyses using Ordinary Last Square method (OLS). The result of the research showed that partially NPL and NIM had positive and not significant influence on ROA, but LDR and BOPO had negative and significant influence on ROA.
\end{abstract}

Keywords: financial ratio, and bank performance.

\section{Pendahuluan}

Perbankan mempunyai peran yang sangat vital dalam pencapaian tujuan nasional yang berkaitan dalam peningkatan dan pemerataan taraf hidup masyarakat serta menunjang berjalanya roda perekonomian mengingat fungsinya sebagai lembaga intermediasi, penyelenggara transaksi pembayaran, serta alat tranmisi kebijakan moneter. Salah satu fungsi penting perbankan yaitu sebagai intermediasi kunci keuangan, yang dimana perbankan bertindak sebagai perantara dalam pemindahan dana dari kalangan penabung kepada pihak lain yang melakukan investasi dalam aktiva riil seperti fasilitas produksi, peralatan dan gedung. Intermediasi keuangan dapat meningkatkan efisiensi ekonomi dengan menghimpun dana lebih dari jutaan penabung dan menyediakannya bagi kalangan investor guna mendukung kegiatannya. Funsi intermediasi keuangan ini dapat meningkatkan kesejahteraan baik bagi pihak penabung maupun investor. (Puspopranoto, 2004).

Perbankan sebagai badan usaha yang bergerak di bidang keuangan atau finansial sangat membutuhkan kepercayaan dari masyarakat guna mendukung dan memperlancar segala kegiatan yang ada di dalam perbankan tersebut. Kinerja merupakan suatu keunggulan yang dicapai oleh suatu perusahaan ataupun bank dalam periode tertentu yang memberi gambaran mengenai kondisi keuangan bank tersebut. Oleh karena itu apabila kinerja perbankan buruk, maka kepercayaan nasabah terhadap perbankan akan menurun dan hal tersebut akan memberi dampak negatif terhadap kegiatan yang akan berlangsung pada perbankan tersebut. Lancarnya kegiatan yang dilakukan oleh bank dan tingginya tingkat kepercayaan masyarakat pada bank maka akan meningkatkan kualitas bank tersebut.

Penelitian ini menggunakan analisis rasio profitabilitas sebagai variabel independen yang biasanya menggunakan Return On Assets (ROA). Alasan dipilihnya ROA, karena ROA memfokuskan kemampuan bank dalam mengelola aset perbankan dalam menghasilkan laba. ROA digunakan untuk mengukur efektifitas perusahaan dalam menghasilkan keuntungan dengan memanfaatkan aktiva yang dimilikinya. ROA merupakan rasio antara laba sesudah pajak terhadap total assets. Semakin besar ROA menunjukkan kinerja

1 Penulis Korespondensi 
perbankan semakin baik, karena tingkat pengembalian (return) semakin besar. Variabel independen yang digunakan dalam penelitian ini merupakan variabel yang menurut penelitian sebelumnya memiliki pengaruh terhadap kinerja bank. Variabel-variabel tersebut adalah Net Interest Margin (NIM), Non Performing Loan (NPL), Loan to Deposit Ratio (LDR), dan Biaya Operasional terhadap Pendapatan Operasional (BOPO).

Net Interest Margin (NIM) adalah pendapatan bank yang utama dan sangat menentukan besarnya pendapatan bersih (income) bank. Besar kecilnya spread (net margin) tergantung kepada besarnya volum kredit yang disalurkan bank (Leon dan Ericson, 2007:102). NIM merupakan rasio antara pendapatan bunga bersih terhadap Outstanding Credit. Pendapatan diperoleh dari bunga yang diterima dari pinjaman yang diberikan dikurangi dengan biaya bunga dari sumber dana yang dikumpulkan. NIM memiliki hubungan positif dengan perubahan laba yang berarti bahwa apabila rasio NIM meningkat maka perubahan laba yang dihasilkan juga akan meningkat (Aini, 2013). Dengan demikian, NIM mempengaruhi laba-rugi bank yang juga akan berpengaruh pada kinerja bank.

Non Performing Loan (NPL) adalah kredit yang kategori kolektibilitasnya diluar kolektibilitas kredit lancar dan kredit dalam perhatian khusus. Kredit bermasalah mencakup kredit kurang lancar, diragukan, dan macet (Leon dan Ericson,2007:95). Menurut Hasibuan dalam (Dewi et al, 2015) rasio NPL digunakan untuk mengukur kemampuan manajemen bank dalam mengelola kredit bermasalah yang diberikan oleh bank. Risiko kredit yang diterima oleh bank merupakan salah satu risiko usaha bank, yang diakibatkan dari ketidakpastian dalam pengembaliannya atau yang diakibatkan dari tidak dilunasinya kembali kredit yang diberikan oleh pihak bank kepada debitur. Semakin tinggi rasio ini maka akan semakin buruk kualitas kredit bank yang menyebabkan jumlah kredit bermasalah semakin besar dan menyebabkan kerugian, sebaliknya jika semakin rendah NPL maka laba atau profitabilitas bank tersebut akan semakin meningkat.

Loan Deposit Ratio (LDR) menyatakan seberapa jauh kemampuan bank dalam membayar kembali penarikan dana yang dilakukan nasabah dengan mengandalkan kredit yang diberikan sebagai sumber likuiditasnya (Leon dan Ericson, 2007: 80). Semakin tinggi LDR maka laba bank juga akan semakin meningkat asalkan bank tersebut mampu menyalurkan kreditnya dengan baik. Semakin meningkatnya laba bank, maka hal tersebut juga akan memberi pengaruh terhadap kinerja bank.

Rasio Biaya Operasional (BOPO), adalah rasio perbandingan antara Biaya Operasional dengan Pendapatan Operasional, semakin rendah tingkat rasio BOPO berarti semakin baik knerja manajemen bank tersebut, karena lebih efisien dalam menggunakan sumber daya yang ada di perusahaan (Restiyana dan Mahfud, Tanpa tahun). Meningkatnya biaya operasional, terutama overhead cost mempengaruhi besarnya tingkat suku bunga kredit (lending rate). Jika suku bunga kredit suatu bank tidak dapat bersaing dengan tingkat suku bunga pasar, maka alokasi dana perkreditan bank tersebut tidak dapat diserap oleh pasar sehingga dapat dipastikan bahwa bank tersebut akan menanggung biaya yang besar sehimgga pada akhirnya akan merugikan bank (Leon dan Ericson, 2007:17)

Alasan dipilihnya industri perbankan karena kegiatan bank sangat diperlukan bagi lancarnya kegiatan perekonomian di sektor riil. Sektor riil tidak akan dapat berkinerja dengan baik apabila sektor moneter tidak bekerja dengan baik.

\section{Metode}

Jenis data yang digunakan dalam penelitian ini adalah data sekunder berupa time seriesdengan rentan waktu penelitian dari tahun 2008 sampai dengan 2015 yang bersumber dari data yang dipublikasikan oleh Otoritas Jasa Keuangan (OJK) dan Bank Indonesia.Variabel dependent yang digunakan adalah Return On Aset (ROA) dan variabel independentnya terdiri dari Net Interest Margin (NIM), Non Performing Loan (NPL), dan Loan Deposit Ratio (LDR) Biaya Operasional dan Pendapatan Operasional (BOPO).

Penelitian ini menggunakan metode Ordinary Least Square (OLS). Adapun model dasar yang digunakan dalam penelitian ini adalah:

$$
\mathrm{Y}=\mathrm{a}+\mathrm{b} 1 \mathrm{X} 1+\mathrm{b} 2 \mathrm{X} 2+\mathrm{b3} \times 3+\mathrm{b} 4 \mathrm{X} 4+\mathrm{e}
$$

dimana:

$\begin{array}{ll}\mathrm{Y} & =\text { variabel dependen }(\mathrm{ROA}) \\ \mathrm{X} 4 & =\mathrm{NPL} \\ \mathrm{X} 2 & =\mathrm{LDR} \\ \mathrm{X} 3 & =\mathrm{NIM} \\ \mathrm{X} 4 & =\text { BOPO. }\end{array}$

\section{Hasil}

\section{Hasil dan Pembahasan}

Tabel 1 Nilai mean, median, maximum, minimum, standard deviasi dari masing-masing variabel

\begin{tabular}{|c|c|c|c|c|c|}
\hline & ROA & NPL & LDR & $\begin{array}{l}\mathrm{N} \\
\mathrm{I}\end{array}$ & BOPO \\
\hline Mean & 2.845313 & $\begin{array}{c}3.9028 \\
12\end{array}$ & 81.35625 & $\begin{array}{l}5 \\
.\end{array}$ & 82.91688 \\
\hline Median & 2.955000 & $\begin{array}{c}3.8216 \\
67\end{array}$ & 80.62500 & $\begin{array}{l}5 \\
.\end{array}$ & 85.67000 \\
\hline Max & 3.160000 & $\begin{array}{c}4.9266 \\
67\end{array}$ & 92.11000 & $\begin{array}{l}5 \\
.\end{array}$ & 90.68000 \\
\hline Min & 2.290000 & $\begin{array}{c}2.9400 \\
00\end{array}$ & 70.66000 & $\begin{array}{l}4 \\
.\end{array}$ & 74.08000 \\
\hline $\begin{array}{l}\text { Std. } \\
\text { Dev }\end{array}$ & 0.269120 & $\begin{array}{c}0.5259 \\
07\end{array}$ & 6.763398 & $\begin{array}{l}0 \\
.\end{array}$ & 6.248194 \\
\hline Obs & 32 & 32 & 32 & $\begin{array}{l}3 \\
2\end{array}$ & \\
\hline
\end{tabular}

\section{Hasil Estimasi Ordinary Least Square (OLS)}

Tabel 2 Hasil estimasi OLS

\begin{tabular}{cccccc}
\hline & $\mathrm{C}$ & $\mathrm{b}_{1}$ & $\mathrm{~b}_{2}$ & $\mathrm{~b}(\mathrm{NIMt})$ & $\begin{array}{c}\mathrm{B}_{4} \\
(\mathrm{NPL})\end{array}$ \\
\hline Coefficient & 7.752 & 0.092 & -0.024 & 0.11 & -0.047009 \\
\hline
\end{tabular}




\begin{tabular}{lccccc}
\hline t-statistic & 5.564 & 1.055 & -2.379 & 1.117 & -5.485669 \\
\hline Prob & 0.0000 & 0.3007 & 0.0247 & 0.2737 & 0.0000 \\
\hline
\end{tabular}

\begin{tabular}{ll}
\hline Adj.R-Sqs & 0.544704 \\
\hline Prob F-stat & 0.000204
\end{tabular}

Hasil estimasi pada tabel 2 menunjukkan bahwa variabel LDR dan BOPO signifikan mempengaruhi kinerja Bank Umum di Indonesi dengan nilai t-hitung lebih kecil daripada t-tabel atau dengan cara melihat probabilitas t-hitung pada variabel LDR dan BOPO yaitu sebesar 0.0247 dan 0.000 yang lebih kecil daripada $\alpha(\alpha=5 \%=0,05)$, sedangkan variabel NPL dan NIM tidak signifikan dalam mempengaruhi kinerja Bank Umum di Indonesia karena t-hitung lebih besar daripada t-tabel yaitu 0.3007 dan 0.2737 lebih besar daripada $\alpha(\alpha=$ $5 \%=0,05)$. Variabel LDR dan BOPO memiliki pengaruh yang negatif dan signifikan terhadap kinerja Bank Umum di Indonesia. Variabel NPL dan NIM memiliki pengaruh yang positif dan tidak signifikan terhadap kinerja Bank Umun di Indonesia. Secara keseluruhan, keempat variabel independent berpengaruh secara signifikan terhadap kinerja Bank Umum di Indonesia yang dilihat dari nilai probabilitas F-hitung yaitu 0.000204 lebih kecil daripada $\alpha(\alpha=5 \%)$.Keterangan Hasil Estimasi Model Regresi Linier Berganda :

a) Nilai konstanta $\mathrm{C}$ sebesar 7.752017 artinya ketika variabel NPL, LDR, NIM, dan BOPO sama dengan nol, maka kinerja bank (ROA) adalah sebesar $7.752017 \%$

b) Variabel NPL mempunyai koefisien regresi sebesar 0.092697 menunjukkan pengaruh positif yang berarti apabila variabel NPL mengalami peningkatan sebesar $1 \%$ sedangkan variabel bebas lainnya dianggap tetap, maka akan akan menyebabkan kinerja bank (ROA) akan meningkat sebesar $0.092697 \%$

c) Variabel LDR mempunyai koefisien regresi sebesar -0.024196 menunjukkan pengaruh negatif yang berarti apabila variabel LDR mengalami peningkatan sebesar $1 \%$ sedangkan variabel bebas lainnya dianggap tetap, maka akan akan menyebabkan kinerja bank (ROA) akan menurun sebesar $0.024196 \%$

d) Variabel NIM mempunyai koefisien regresi sebesar 0.110977 menunjukkan pengaruh positif yang berarti apabila variabel NIM mengalami peningkatan sebesar $1 \%$ sedangkan variabel bebas lainnya dianggap tetap, maka akan akan menyebabkan kinerja bank (ROA) akan meningkat sebesar $0.110977 \%$

e) Variabel BOPO mempunyai koefisien regresi sebesar -0.047009 menunjukkan pengaruh negatif yang berarti apabila variabel BOPO mengalami peningkatan sebesar $1 \%$ sedangkan variabel bebas lainnya dianggap tetap, maka akan akan menyebabkan kinerja bank (ROA) akan menurun sebesar $0.047009 \%$

\section{Pembahasan}

\section{Pengaruh NPL terhadap Kinerja Bank Umum di Indonesia}

Hasil estimasi pada Non-Performing Loans (NPL) menyatakan bahwa variabel NPL berpengaruh positif dan

tidak signifikan terhadap variabel terikat kinerja bank (ROA). Karena kredit yang disalurkan tidak memiliki kualitas yang baik dan proses penyalurannya tidak dilakukan sesuai dengan proses yang seharusnya, serta tidak menggunakan prinsip kehati-hatian dalam setiap proses penyaluran yang dapat menyebabkan bank akan menanggung risiko yang cukup besar. Risiko yang dimaksud dapat berupa kesulitan pengembalian kredit oleh debitur dan apabila jumlahnya sangat besar dapat mempengaruhi kinerja bank karena kelancaran debitur dalam membayar kewajiban baik angsuran pokok beserta bunga, merupakan kewajiban agar kegiatan operasional bank tetap berjalan dengan lancar.

\section{Pengaruh LDR terhadap Kinerja Bank Umum di Indonesia}

Hasil estimasi pada Loan Deposite Ratio (LDR) menyatakan bahwa variabel LDR berpengaruh negatif dan signifikan terhadap variabel terikat kinerja bank (ROA). Artinya meningkatnya LDR dapat menurunkan ROA. Penurunan nilai ROA pada bank bisa saja terjadi karena semakin besarnya LDR atau semakin besarnya nilai kredit akan menyebabkan tingginya risiko kredit. Makin tingginya LDR yang berarti makin rendahnya likuiditas menyebabkan profitabilitas yang rendah pula. Hal ini disebabkan terdapatnya Non Performing Loan (NPL) menyebabkan kredit yang disalurkan tidak memberikan hasil. Dan apabila kredit yang disalurkan bermasalah atau mengalami kegagalan (Non Performing Loan/NPL) maka bank akan mengalami kesulitan untuk mengembalikan dana yang dititipkan oleh masyarakat yang pada akhirnya akan berdampak pada penurunan laba.

\section{Pengaruh NIM terhadap Kinerja Bank Umum di Indonesia}

Hasil estimasi pada Net Interest Margin (NIM) menyatakan bahwa variabel NIM berpengaruh positif dan tidak signifikan terhadap variabel terikat kinerja bank (ROA). Variabel NIM pada penelitian ini berpengaruh positif, yang berarti semakin besarnya nilai NIM, maka akan semakin baik pula kinerja bank (ROA). Variabel NIM pada penelitian ini tidak memiliki pengaruh signifikan terhadap kinerja bank (ROA) yang dimana hal tersebut tidak sesuai dengan hipotesis karena pendapatan bank yang diperoleh dari dana yang berbentuk pinjaman atau kredit tidak mempengaruhi laba, yang disebabkan oleh ROA yang lebih dipengaruhi oleh aktivitas operasional bank.

\section{Pengaruh BOPO terhadap Kinerja Bank Umum di Indonesia}

Hasil estimasi pada Biaya Operasional dan Pendapatan Operasional (BOPO) menyatakan bahwa variabel BOPO berpengaruh negatif dan signifikan terhadap variabel terikat kinerja bank (ROA) yang sesuai dengan hipotesis. Semakin kecil nilai variabel BOPO menunjukkan semakin efisien pula bank dalam mempergunakan sumber daya yang ada serta mampu menjalankan kegiatan operasionalnya denga sebaik mungkin. Semakin efisiennya bank, maka kesempatan untuk mendapatkan keuntungan yang tinggi akan sangat besar karena bank telah dapat mengurangi bentuk kegiatan yang tidak menguntungkan. 


\section{Simpulan}

1. Variabel NPL berpengaruh positif dan tidak signifikan yang dimana hal ini tidak sesuai hipotesis karena kredit yang disalurkan tidak memiliki kualitas yang baik dan proses penyalurannya tidak dilakukan sesuai dengan proses yang seharusnya, yang dapat menyebabkan bank akan menanggung risiko berupa kesulitan pengembalian kredit oleh debitur dan apabila jumlahnya sangat besar dapat mempengaruhi kinerja bank karena kelancaran debitur dalam membayar kewajiban baik angsuran pokok beserta bunga, merupakan kewajiban agar kegiatan operasional bank tetap berjalan dengan lancar.

2. Variabel LDR berpengaruh negatif dan tidak signifikan yang dimana tidak sesuai hipotesis karena terdapatnya Non Performing Loan (NPL) menyebabkan kredit yang disalurkan tidak memberikan hasil. Dan apabila kredit yang disalurkan bermasalah atau mengalami kegagalan (Non-Performing Loan/NPL) maka bank akan mengalami kesulitan untuk mengembalikan dana yang dilakukan deposan dengan mengandalkan kredit sebagai sumber likuiditasnya yang yang pada akhirnya akan berdampak pada penurunan laba.

3. Variabel NIM berpengaruh positif dan tidak signigikan. Variabel NIM tidak memiliki pengaruh signifikan terhadap kinerja (ROA) yang dimana hal ini tidak sesuai hipotesis dikarenakan pendapatan bank yang diperoleh dari dana yang berbentuk pinjaman atau kredit tidak mempengaruhi laba, yang disebabkan oleh ROA yang lebih dipengaruhi oleh aktivitas operasional bank.

4. Variabel BOPO berpengaruh negatif dan signifikan terhadap kinerja yang sesuai dengan hipotesis. Semakin kecil nilai BOPO menunjukkan semakin efisien bank dalam mempergunakan sumber daya yang ada serta mampu menjalankan kegiatan operasionalmya dengan baik.

\section{Saran}

1. Dalam menjaga kondisi pergerakan NPL maka bank harus mampu menggunakan prinsip kehati-hatian dalam menyalurkan kredit, bank harus mempertahankan kinerja bank dalam mengelola kredit sehingga dapat mempertahankan persentase kredit macet dibawah batas minimal 5\% yang ditetapkan oleh Bank Indonesia.

2. Kenaikan likuiditas bank dapat menyebabkan tingginya risiko dari kredit macet dan adanya peningkatan kredit macet tentunya dapat mengurangi kemampuan bank dalam menciptakan laba, upaya yang dapat dilakukan oleh bank untuk meningkatkan kinerja bank ROA adalah dengan memperbaiki kualitas pemberian kredit atau pinjaman kepada nasabah melalui penilaian nasabah kredit yang lebih ketat untuk menekan NPL dan nuga melakukan analisis kredit yang lebih akurat dan lebih selektif sehingga dapat mengurangi atau terhindar dari kredit yang bermasalah.

3. Agar ROA meningkat, pihak manajemen bank harus mampu meningkatkan nilai NIM dari waktu ke waktu. Untuk dapat meningkatkan perolehan Net Interest Margin (NIM) maka bank perlu menekan biaya dana, biaya dana yang dimaksud adalah bunga yang dibayarkan oleh bank kepada masing-masing sumber dana bank yang bersangkutan.

4. Untuk meningkatkan efisiensi, pihak manajemen bank harus dapat menekan biaya operasional yang dapat meningkatkan keuntungan bank.

\section{Ucapan Terima Kasih}

Penulis mengucapkan terima kasih kepada Badan Pusat Statistik Jember yang telah memberikan bantuan untuk data penelitian dan pihak lain yang turut mendukung dalam penelitian ini.

\section{Referensi}

Adenan, M. 2002. Manajemen Perbankan, Jember. Laboratorium Perbankan Fakultas Ekonomi Universitas Jember

Aini, N. 2013. Pengaruh CAR, NIM, LDR, NPL, BOPO, dan Kualitas Aktiva Produktif terhadap Perubahan Laba (Studi Empiris Pada Perusahaan Perbankan Yang Terdaftar Di Bei) Tahun 2009-2011. Dinamika Akuntansi, Keuangan dan Perbankan Vol 2. No,1. Mei 2013, 14-15

Dewi, Herawati, dan Sulindawati. 2015. Analisis Pengaruh NIM, BOPO, LDR, Dan NPL Terhadap Profitabilitas (Studi Kasus Pada Bank Umum Swasta Nasional Yang Terdaftar Pada Bursa Efek Indonesia Periode 2009-2013 ). e-Journal S1 Ak. Universitas Pendidikan Ganesha Jurusan Akuntansi Program S1 Volume: 3 No. 1 Tahun 2015

Leon dan Ericson. 2007. Manajemen Aktiva Pasiva Bank Nondevisa. Jakarta: PT Grasindo

Puspopranoto, S. 2004. Keuangan Perbankan dan Pasar Keuangan. Jakarta: Pustaka LP3ES Indonesia

Restiyana \& Mahfud. Tanpa Tahun. Analisis Pengaruh CAR, NPL, BOPO, LDR, dan NIM Terhadap Profitabilitas Perbankan (Studi pada bank umum di Indonesia periode 2006-2010). Semarang: Universitas Diponegoro

Sinungan, Muchdarsyah. 1992. Uang dan Bank. Jakarta. Rhineka Cipta

Soediyono. 1989. Ekonomi Makro: Pengantar Analisis Pendapatan Nasional.Edisi 5. Yogyakarta. Liberty. 